\title{
Analysis of Noise Transmitted to Workers in Motor-Manual Forest Harvesting in Minas Gerais State
}

\author{
Dâmaris Billo $^{1}$ (D), Luan Mendes ${ }^{1}$ (D), Glícia Nascimento ${ }^{1}$ (D), Nilton Fiedler ${ }^{1}$ (D), \\ Leandro Berude ${ }^{1}$ \\ ${ }^{1}$ Programa de Pós-graduação em Ciências Florestais, Universidade Federal do Espírito Santo - UFES, \\ Jerônimo Monteiro/ES, Brasil
}

\begin{abstract}
Noise can entail irreversible damage to the health of workers exposed to this factor. Thus, this work aimed to evaluate noise levels emitted by chainsaws during forest cutting activity. Noise measurements were performed with dosimeters on the workstation and compared to NR15. The noise dose average of all activities in the operation studied exceeded the maximum allowable limit of $85 \mathrm{~dB}(\mathrm{~A})$ for 8 hours of continuous work, exposing operators to noise levels that may cause health and physical damages. The most critical situation occurred on felling activity, evidencing the lack of acting in the chainsaws designs aiming to reduce noise levels. The results highlight the requirement to use PPE's suitable for activities, such as hearing dampers, and point to the need to develop research and new equipment with less noisy sources that aim at maintaining the health of the harvesting operators.
\end{abstract}

Word keys: forestry techniques and operations; ergonomics; occupational health; forest cutting. 


\section{INTRODUCTION}

The Brazilian planted forests industry is a world reference for its innovative development. Currently, the sector is responsible for $1.1 \%$ of all the wealth generated in the country, guaranteeing the public coffers $\mathrm{R} \$ 11.4$ billion in taxes per year and providing 3.7 million of jobs (IBÁ, 2017).

Brazil has more than 7.8 million hectares covered by planted forests -5.7 million occupied by eucalyptus plantations - mainly located in the states of Minas Gerais, São Paulo and Mato Grosso do Sul (IBÁ, 2017).

Some Brazilian states, such as Minas Gerais and Espírito Santo, have most of their forest plantations on a small scale and under a sloping relief. This characteristic makes unfeasible the machinery traffic and the harvest mechanization, thus predominating the use of the cut with chainsaw (Pescador et al., 2013).

A constant ergonomic reorganization is essential to improve working conditions (Berude et al., 2018). In this sense, ergonomics is a set of sciences that seek the adaptation between worker and work through several studies, such as the evaluation of the noise level (Pires et al., 2013).

Ganime et al. (2010), studying noise in labor environment, found two definitions for noise. According to them, noise is explained by Velasquez et al. (2005) as an unpleasant sound, and by Mesquita et al. (2007) as any discomfort and/or intolerance resulting from a sound exposure. Regardless of the different definitions, the authors agree that noise changes physically and psychologically the human being, causing irreversible injuries or making the worker truly neurotic.

According to Santos et al. (2015), high noise levels may cause the worker hearing reduction or loss, reducing the comfort and performance of the human being and machine set. Other factors extra auditory caused by the continued exposure to noise highlighted in the literature are: irritability, anxiety, nervousness, vertigo, increased frequency and respiratory depth, pulse acceleration, elevation of blood pressure, contraction of vessels blood, insomnia, reduced libido, increased muscle tone, difficulty of body rest, and muscular spasms (Nunes et al., 2011; Ganime et al., 2010).

In order to avoid the occurrence of the aforementioned problems and regulate the times and levels of noise to which workers are exposed, the Brazilian legislation NR15 - Annex 1 specified a maximum exposure time allowed for each noise level.

NR15 provides that the maximum noise level for an 8 -hour exposure per day is $85 \mathrm{~dB}(\mathrm{~A})$ and for each $5 \mathrm{~dB}(\mathrm{~A})$ increase in the noise level above this limit the exposure time should be halved (Fiedler et al., 2010). In addition, noise levels are additive, i.e. two machines together produce a louder sound than each machine working in isolation.

Considering the above, the objective of this work was to analyze the noise level transmitted to chainsaw operators during the stages of the motor-manual forest harvesting and to compare it with the current Brazilian legislation.

\section{MATERIAL AND METHODS}

\subsection{Study area}

The evaluation tests of noise levels emitted by chainsaws were held in Eucalyptus cloeziana settlements with 6 years old, planted with initial spacing of $3 \times 2 \mathrm{~m}$ in an area of 6.3 hectares for energy purposes.

The planting was located in the municipality of Itabira, Minas Gerais State, Brazil. The region's relief is hilly, with altitudes ranging from 540 to $1,662 \mathrm{~m}$. The climate is warm and seasoned, classified as Cwa on the Köppen and Geiger scales. The annual temperature average is $20.4{ }^{\circ} \mathrm{C}$ and the annual rainfall average is $1,471 \mathrm{~mm}$.

\subsection{Population and sampling}

The population studied was six employees that performed forest cutting activity, corresponding to the total population of operators in the function of chainsaw operator.

The research was conducted from a survey of the forest cutting operation, verifying the minimum number of samples for a $5 \%$ error of significance by the Conaw method, as the equation 1 (Diniz et al., 2018; Maziero et al., 2018; Lopes et al., 2016):

$\mathrm{N} \geq \frac{\mathrm{t}^{2} \times \mathrm{s}^{2}}{\mathrm{e}^{2}}$ 
Where: N: Minimum number of samples required, $t$ : Tabled coefficient of Student T, s: Standard deviation, and e: Admitted error.

\subsection{Work system}

Chainsaw operators had a work shift of 8 hours a day, from 7:00 a.m. to 4:00 p.m., with one-hour lunch break. They used personal protective equipment (PPE): pants, helmet, ear protector, face protector, goggles, gloves, gaiters and security footwear.

\subsection{Evaluated activities}

The forest cutting operation consists on the first step of the wood harvesting, performed after the pre-cut mowing. In this study the cutting method analyzed was the motor-manual one, with the use of chainsaw. The activities involved felling, delimbing (with trimming) and logging in the $1+1$ system (an operator and a helper). The cutting group was three lines.

The tree cutting was performed with STIHL chainsaws model MS361, weighing $5.6 \mathrm{~kg}$. During the operation, the worker walked through the forest section felling all trees in the first row of the cutting group and returned the same way delimbing these trees. In the sequence, the operators performed the same actions in the consecutive rows of the cutting group.

The logging consisted of the stem sectioning into $2 \mathrm{~m}$ logs, adapting to market requirements and specifications. This activity was carried out by the operator after felling and delimbing all the cutting group trees, while the helper cobbled together the branches and stacked the logs.

\subsection{Data collection}

Noise levels produced by the chainsaws in work fronts were obtained with the DOS-500 dosimeter, Instrutherm brand. It was verified the daily dose the worker received individually. The capture of noise levels was performed in each evaluated activity.

The noise assessment was made throughout the working day respecting the sample intensity, noting the schedules of all activities and their breaks, subsequently separated in minute-to-minute intervals in the dosimeter software. The collections occurred from April to June 2017.
To get the readings, the device was positioned in the operator's clothing with the dosimeter microphone positioned at the height of the worker's ear throughout all the work shift. The response circuit used in sound pressure level measurements was the slow response (slow), commonly used for occupational noise, with the weighting circuit " $A$ ", used to measure continuous or intermittent noises.

\subsection{Statistical data analysis}

Noise data on the work environment was analyzed in the three studied activities by means of the variance analysis with the use of the $\mathrm{F}$ test at $1 \%$ of probability. Analyses in which there were significant differences, it was held the Tukey test to $1 \%$ of probability.

\section{RESULTS AND DISCUSSION}

As shown in table 1, the sampling was significant to $5 \%$ probability by the $\mathrm{T}$ test in all forest cutting activities evaluated.

The results of average noise levels emitted by the chainsaws during forest cutting activities were $102.05 \mathrm{~dB}(\mathrm{~A})$ for the felling, $99.20 \mathrm{~dB}(\mathrm{~A})$ for the logging and $95.14 \mathrm{~dB}(\mathrm{~A})$ for delimbing (Graphic 1).

For all evaluated activities noise was greater than $85 \mathrm{~dB}(\mathrm{~A})$, the maximum permissible dose for 8 -hour work shift.

Exposure to high noise levels in the working environment may imply worker's hearing loss and other problems. According to Nunes et al. (2011), workers exposed to noise greater than $85 \mathrm{~dB}(\mathrm{~A})$ often experience tinnitus, discomfort to loud sounds, gastric disturbances, and anxiety; and these symptoms intensify with time.

It is important to emphasize that the average value of $78.67 \mathrm{~dB}(\mathrm{~A})$ found for the moment of rest is within

Table 1. Evaluated activities from forest cutting, number of collected samples and minimum number of samples needed (n).

\begin{tabular}{|c|c|c|}
\hline $\begin{array}{c}\text { Evaluated } \\
\text { Activity }\end{array}$ & $\begin{array}{c}\text { Number of } \\
\text { Collected } \\
\text { Samples }\end{array}$ & $\mathbf{n}$ \\
\hline Felling & 100 & 82 \\
\hline Delimbing & 100 & 81 \\
\hline Logging & 100 & 67 \\
\hline
\end{tabular}


the tolerable noise level for an 8-hour work journey. But, for the purpose of stopping for food and rest, it is above the levels considered comfortable. For comfort maintenance, the maximum noise exposure value must be below to $65 \mathrm{~dB}(\mathrm{~A})$ according to the NR-17, normative which deals with ergonomics in the work environment.

The high value found for the rest is justified by the permanency of operators in the field, close to other activities that generate noises. Applying, in this case, the recommendation of holding pauses outside the working environment, in quiet and less noisy environments (Souza et al., 2015).

Such values corroborate the need for operators to be aware of the importance of using personal protective equipment (PPE) to mitigate exposed noise.

Brazilian legislation establishes that the limits of daily occupational exposure to noise for an 8-hour work shift without the use of hearing PPE is $85 \mathrm{~dB}(\mathrm{~A})$. Based on this value, for every $5 \mathrm{~dB}(\mathrm{~A})$ (doubling increment) of noise elevation, the exposure time should be halved (Fiedler et al., 2010).

Thus, with the data found in the evaluation, it is possible to establish the maximum daily exposure an operator without PPE supports without its health, safety and welfare getting harmed, as presented in Table 2.

In the three activities of the cutting operation, the noise factor was not compliant with the recommended, demanding a reduction in the working day of the operator.

Studying the influence of noise on hearing loss, Boger et al. (2009) observed that the use of PPE is not totally effective, since the workers under study developed some auditory damage even with the use of hearing dampers. So, independent of the PPE use, a fatigue recovery time value equivalent to $5 \%$ of the working day for workers exposed to noise levels between 86 and $95 \mathrm{~dB}(\mathrm{~A})$ should be attributed.

Worker recovery breaks are extremely necessary. Although the use of hearing damper allows noise levels reduction, it does not fully protect the worker from noise exposure. In a study carried out by Vosniak et al. (2011) with workers in the activity of dibbling, even with the use of hearing dampers there were found noise levels exceeding the limit set by NR 15 .

This is highlighted by Pessina \& Guerretti (2000) when they evaluated the efficiency of various noise reduction devices in agricultural tractor operators.

\section{Chainsaw noise level (8-hour work shift)}

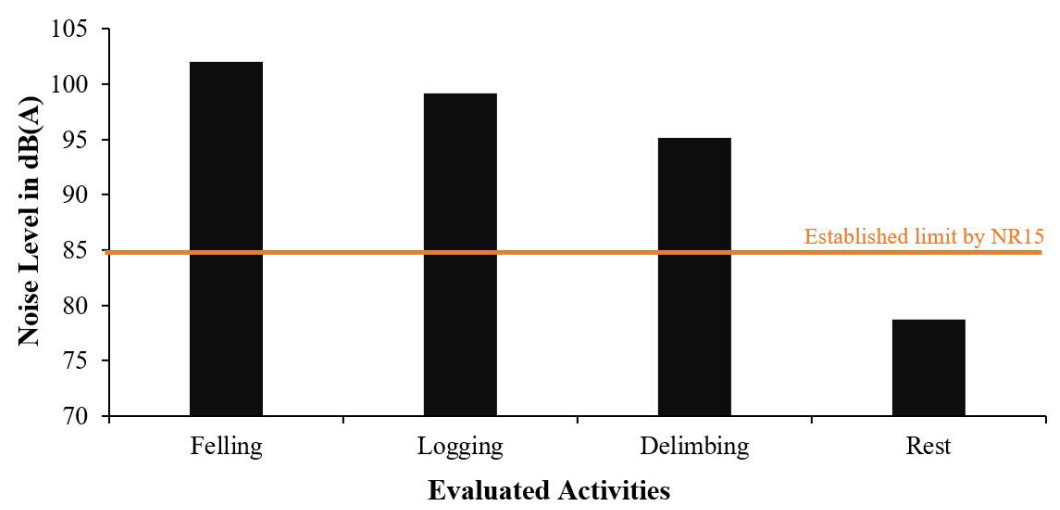

Graphic 1. Noise level in $\mathrm{dB}(\mathrm{A})$ emitted by the chainsaw during the working day of motor-manual harvesting activity.

Table 2. Maximum daily exposure permissible without PPE for each evaluated activity.

\begin{tabular}{ccc} 
Evaluated Activity & Noise Level dB(A) & $\begin{array}{c}\text { Maximum Daily Exposure } \\
\text { Permissible (without PPE) }\end{array}$ \\
Felling & 102.05 & 45 minutes \\
Logging & 99.2 & 1 hour \\
Delimbing & $95.14 \mathrm{DB}$ & 1 hour and 45 minutes \\
\hline
\end{tabular}


The authors concluded that, on average, hearing protection devices provide noise level reduction in the order of $10 \mathrm{~dB}(\mathrm{~A})$. Considering this value, even with the attenuation of an efficient hearing damper, in fact, the noise levels found in this work would still be higher than the recommended.

\section{CONCLUSION}

All operations of the motor-manual forest cut showed noise levels above that permitted by the Brazilian legislation for unhealthy activities. The most critical situation was found in the felling operation, followed by logging and delimbing.

The noise factor in the cut with chainsaws is not in accordance with the Brazilian legislation in force, requiring recovery breaks for workers and reducing working hours.

The chainsaws used in the evaluated activities can cause damage to the health and physical integrity of the operators, emphasizing the necessity of using PPE's suitable for activities, such as hearing dampers. It points to the need of developing research and new equipment with less noisy sources that aim at maintaining the health of harvesting operators.

\section{ACKNOWLEDGEMENTS}

The authors thank the UFES, CNPQ, CAPES and FAPES.

\section{SUBMISSION STATUS}

Received: 30 oct., 2018

Accepted: 4 dec., 2018

\section{CORRESPONDENCE TO}

\section{Dâmaris Billo}

Avenida Governador Lindemberg, 316, Centro, Jerônimo, CEP 29550-000, Monteiro, ES, Brasil e-mail: damaris_billo@hotmail.com

\section{FINANCIAL SUPPORT}

The authors thank the support provided by Fundação Estadual de Amparo à Pesquisa do Estado do Espírito Santo (FAPES) - edital PROCAP no. 08/2017; Conselho
Nacional de Desenvolvimento Científico e Tecnológico (CNPq) and Coordenação de Aperfeiçoamento de Pessoal de Nível Superior (CAPES) - Código de Financiamento 001.

\section{REFERENCES}

Berude LC, Fiedler NC, Carmo FCA, Gonçalves SB, Canzian WP. Postures adopted by workers in the implantation and maintenance of production forests. ACSA 2018; 14(1): 13-20.

Boger ME, Barbosa-Branco A, Ottoni AC. The noise spectrum influence on Noise-Induced Hearing Loss prevalence in workers. Revista Brasileira de Otorrinolaringologia 2009; 75(3): 328-334. http://dx.doi.org/10.1016/S18088694(15)30646-7. PMid:19649479.

Diniz CCC, Robert RCG, Vargas MB. Technical evaluation of individual and multiple heads in the processing of wood. Advances in Forestry Science 2018; 5(1): 253-258.

Fiedler NC, Guimarães PP, Alvez RT, Wanderley FB. Ergonomic evaluation of the working environment in marcenaries in the south of Espírito Santo. Arvore 2010; 34(5): 907-915.

Ganime JF, Silva LA, Robazzi MLCC, Sauzo SV, Faleiro SA. Noise as one of the occupational risks: a literature review. Enfermaría Global [online]. 2010 [cited 2018 Oct 25]; (19): 1-15. Available from: http://scielo.isciii. es/pdf/eg/n19/pt_revision1.pdf

Industria Brasileira de Árvores - IBÁ. Report IBÁ 2017 [online]. Brasília, 2017 [cited 2017 Sep 19]. Available from: http://www.iba.org/images/shared/iba_2017.pdf

Lopes ES, Vieira TP, Rodrigues CK. Technical and cost evaluation of road transport with different species and wood dryings. Floresta 2016; 46(3): 297-305. http:// dx.doi.org/10.5380/rf.v46i3.36826.

Maziero R, Fiedler NC, Segundinho PGA, Carmo FCA. Analysis of the physical workload and biomechanics in construction of roofs with structures of wood. Floram 2018; 25(1): 1-10.

Nunes CP, Abreu TRM, Oliveira VC, Abreu RM. Hearing and non-hearing symptoms in workers exposed to noise. RBSP 2011; 35(3): 548-555.

Pescador CMM, Lisboa GS, Stepka TF, Kurchaidt SM. Work Safety in the forest harvesting: initial results. Ambiência 2013; 9(2): 397-410. http://dx.doi.org/10.5777/ ambiencia.2013.02.01nt.

Pessina D, Guerretti M. Effectiveness of hearing protection devices in the hazard reduction of noise from used tractors. Journal of Agricultural Engineering Research 2000; 75(1): 73-80. http://dx.doi.org/10.1006/ jaer.1999.0489. 
Pires LD, Solano JVN, Araujo RCP. Ergonomics: evaluation on post of computerized work held in the center computer application and communication - CAIC TIC. Connexio 2013; 2(2): 85-99.

Santos DWFN, Leite ES, Souza DR, Fernandes HC. Technical-economical analysis of harvesting systems: short and long logs under mechanized and motor-manual methods. Magistra 2015; 27(3-4): 412-423.
Souza AP, Dutra RBC, Minette LJ, Marzano FLC, Schettino S. Production targets for forest-cutting workers. Árvore 2015; 9(4): 713-722.

Vosniak J, Lopes ES, Inoue MT, Batista A. Evaluation of working postures in workers at planting and fertilizing activities in forest plantations. Revista Ceres 2011; 58(5): 584-592. http://dx.doi.org/10.1590/S0034737X2011000500008. 